\title{
Use of Ventilation-Index in the Development of Exposure Model for Indoor Air Pollution-A Review
}

\author{
Krishnendu Mukhopadhyay', Rengaraj Ramasamy¹, Banani Mukhopadhyay², \\ Santu Ghosh1, Sankar Sambandam1, Kalpana Balakrishnan1 \\ ${ }^{1}$ Department of Environmental Health Engineering, ICMR Center for Advanced Research on Environmental \\ Health: Air Pollution, Sri Ramachandra University, Chennai, India \\ 2Department of Chemistry, Women's Christian College, Chennai, India \\ Email: krishnendu@ehe.org.in, rengaraj@ehe.org.in, banalata97@rediffmail.com, santu@ehe.org.in, \\ sankars@ehe.org.in, kalpanasrmc@ehe.org.in
}

Received 8 March 2014; revised 8 April 2014; accepted 16 April 2014

Copyright (C) 2014 by authors and Scientific Research Publishing Inc.

This work is licensed under the Creative Commons Attribution International License (CC BY).

http://creativecommons.org/licenses/by/4.0/

c) (i)

\begin{abstract}
In indoor environment, emission factor of the cooking fuel plays a vital role in determining correlation between exposure assessment and health effects. Both indoor and outdoor air pollution exposures are widely influenced by the ventilation status. An optimum control of the air change rate has also significant impact on the exposure pattern. A number of studies revealed that the indoor particulates and gaseous exposures, resulting from the combustion of various cooking fuels, are associated with significant adverse health effects on pregnant mothers and new born babies. The impacts of ventilation status on air pollution exposure in households' kitchens or living rooms have not been explored enough. Except a few studies with concrete rooms, especially in industries, no other studies have been established on the correlation between the ventilation index and air pollution exposure. The intent of this review is to discuss reported findings focused on the ventilation and exposure to air pollution. This will obviously help better understanding to modulate exposure profile in household condition using simple tool of ventilation measurement.
\end{abstract}

\section{Keywords}

Ventilation Index, Exposure, Air Change Rate, Air Pollution, Health Effects

\section{Introduction}

Human occupancy and activity spoil the air quality in the occupied rooms and give a sense of discomfort to the

How to cite this paper: Mukhopadhyay, K., Ramasamy, R., Mukhopadhyay, B., Ghosh, S., Sambandam, S. and Balakrishnan, K. (2014) Use of Ventilation-Index in the Development of Exposure Model for Indoor Air Pollution-A Review. Open Journal of Air Pollution, 3, 33-41. http://dx.doi.org/10.4236/ojap.2014.32004 
occupants. Unless the contaminated indoor air is replaced by the fresh air, it may adversely affect the comfort, health and the efficiency of the occupants. Occupants may feel suffocation and complain of headache, drowsiness and inability to concentrate.

Ventilation is a critical component of green homes and it plays a vital role in the assessment of human exposure to air pollutants in indoor environment. It is reported that indoor air has a higher concentration of gases and particles compared to outdoor air, typically due to inadequate ventilation combined with high temperature and humidity levels, which can hold a greater concentration of gases. For example, the average outdoor radon level has been found to be $0.4 \mathrm{pCi} / \mathrm{L}$ in comparison to the average indoor radon level $1.3 \mathrm{pCi} / \mathrm{L}$ [1]. Globally, $4.3 \mathrm{mil}$ lion deaths were attributed to exposure to indoor air pollution in developing countries in 2012, almost all in low and middle income countries [2]. Low- and middle-income countries in the WHO South-East Asia and Western Pacific Regions had the largest air pollution-related burden in 2012, with a total of 3.3 million deaths linked to indoor air pollution and 2.6 million deaths related to outdoor air pollution [3].

According to the United States Environmental Protection Agency (USEPA), human exposure to indoor air pollutants may be 2 to 5 times-occasionally more than 100 times higher than outdoor pollutant levels. Indoor air pollutants have been ranked among the top five environmental risks to public health [4]. This is because a home's interior accumulates and concentrates pollutants given off by finishes, furnishings and the daily activities of the occupants. Meteorological parameters such as room temperature, humidity, air density, wind direction and physico-chemical parameters like vapor pressure, specific gravity, diffusion, dispersion, partition co-efficient, evaporation, vaporization etc. contribute a lot in developing exposure model. Other important factors are pollution source, room volume, ventilation type and exposure time [5] [6].

The "Ventilation Index" is a common term used in air pollution. It is a numerical value related to dispersing potential for airborne pollutants in a certain local atmosphere. It is based on both the existing wind speed in the mixed layer and the mixing height. The mixed layer is the surface layer of air that is turbulent and well mixed. The mixing height is the thickness of this mixed layer. Stronger wind speeds and thicker mixed layers will produce higher venting indices. For convenience, the Ventilation Index is converted to a scale of 0 to 100 [7].

But, in normal indoor environment, the air pollution exposure concentration depends largely on the emission factor of the cooking fuel. An emission factor is a representative value that attempts to relate the quantity of a pollutant released to the atmosphere with an activity associated with the release of that pollutant. An air quality emission factor is then related between the amount of pollution produced and the amount of raw material processed. These factors are usually expressed as the weight of pollutant divided by a unit weight, volume, distance, or duration of the activity emitting the pollutant. Such factors facilitate estimation of emissions from various sources of air pollution and to document the emission gradient in indoor environment, measuring ventilation status would be a better option.

Information on emission sources may be available from household questionnaire administration and by the observation of the person engaged in indoor air monitoring process. In general, these processes can be grouped into five categories namely combustion, manufacturing, solvent evaporation, storage and fugitive.

If the concentration of a contaminant in a fuel is known, emissions of that contaminant can be calculated by assuming all of the contaminant emitted prior to the application of an emission control. It should be noted that some of the contaminants require further analysis to determine the portion emitted to the atmosphere, since some of these contaminants may end up in various physical or chemical states and not emitted to the atmosphere. The general equation for the mass balance approach is:

$$
M e=M i-M p-M a-M c
$$

where, $M e=$ Mass of the compound emitted; $M i=$ Mass of the compound in the raw material feed; $M p=$ Mass of the compound in the finishing product; $M a=$ Mass of the compound accumulated in the physical or chemical state; $M c$ = Mass of the compound captured for recovery or disposal.

Basically, an emission factor is the contaminant emission rate relative to the level of source activity. Facility specific established emission factors (mass of emission per unit time, mass of emission per input material flow, or mass of emission per unit output production) will be applicable to the measured processes or similar equipment/processes of other facilities when the operating conditions are comparable. Generic emission factors are commonly used when site-specific source monitoring data are unavailable.

The basic equation used in an emission factor calculation is:

$$
E_{x}=B Q \times E F_{x} \times\left[100-C E_{x}\right] / 100
$$


where: $E_{x}=$ Emission of contaminant $x, \mathrm{~kg} ; B Q=$ Activity rate or base quantity (BQ), BQ unit; $E F_{x}=$ Uncontrolled emission factors of contaminant $x, \mathrm{~kg} / \mathrm{BQ}$ unit; $C E_{x}=$ Overall emission control efficiency of contaminant $x, \%$ or

$$
E_{x}=B Q \times C E F_{x}
$$

where: $E_{x}=$ Emission of contaminant $x, \mathrm{~kg} ; B Q=$ Activity rate or base quantity (BQ), BQ unit; $C E F_{x}=$ Controlled emission factors of contaminant $x, \mathrm{~kg} / \mathrm{BQ}$ unit. ER is further defined as the product of the control device destruction or removal efficiency and the capture efficiency of the control system. When estimating emissions for a long time period, both the device and the capture efficiency terms should account for upset periods as well as routine operations [8].

Data from source-specific emission tests or continuous emission monitors are usually preferred for estimating a source's emissions because those data provide the best representation of the tested source's emissions. However, test data from individual sources are not always available and, even then they may not reflect the variability of actual emissions over time. Thus, in spite of their limitations, emission factors are frequently considered as the best or only method available for estimating emissions.

For estimating ventilation index, the parameter air change per hour (ACH) has also been used in several facilities to describe the volume of air in a building that is replaced per hour through ventilation. As per the Association of German Engineers (VDI), air change is defined as the ratio of air supply $Q(t)$ into a zone (i.e. a room or space) in relation to the volume of this zone VR (room volume)and is generally expressed as air change per hour $\left[\mathrm{h}^{-1}\right]$ or $[\mathrm{ACH}]$. The following equation expresses this definition:

$$
\lambda(t)=Q(t) / V R
$$

where, $\lambda(t)$ is the ventilation rate or air change rate $\left[\mathrm{h}^{-1}\right], Q(t)$ is the air supply into a room $\left[\mathrm{m}^{3} / \mathrm{h}\right], V R$ is the room's volume $\left[\mathrm{m}^{3}\right]$, and $t=$ time [h] [9]. Using this equation they developed a model for air change in indoor room quantified by tracer gas concentration. The basis for the description of the relationship is the mass balance equation. This equation expresses that the mass and-in a fixed volume- the concentration of a tracer gas can only change when either more tracer gas is added to the original amount or tracer gas is removed by elimination processes. Three common methods exist for the determination of air exchange rate (ACR) using tracer gases namely, the concentration decay method, the constant injection method, and the constant concentration method.

The very limited data available suggest that inflammation, respiratory infections, asthma symptoms, and short term sick-leave increase with lower ventilation rates. It is also found that ventilation rates above 0.5 air change rate per hour in homes are associated with a reduced risk of allergic manifestations among children in a Nordic climate [10]. It means ACH above 0.5 attains disperse potential of the toxicants present in indoor environment that is effective in reducing the risk of exposure and health outcomes.

On the other hand, the ventilation effectiveness describes the relation between the pollution concentrations in the supply air, the extract air and the indoor air in the breathing zone (within the occupied zone). It is defined as

$$
\varepsilon V=\frac{C E T A-C S U P}{C I D A-C S U P}
$$

where $\varepsilon_{v}$ is the ventilation effectiveness, $C_{E T A}$ is the pollution concentration in the extract air, $C_{I D A}$ is the pollution concentration in the indoor air (breathing zone within in the occupied zone) and $C_{S U P}$ is the pollution concentration in the supply air. The ventilation effectiveness depends on the air distribution and the kind and location of the air pollution sources in the space. It may therefore have different values for different pollutants. If there is complete mixing of air and pollutants, the ventilation effectiveness is one [11].

Carbon dioxide has been an effective choice as a good tracer gas since it holds almost similar molecular weight as of air and is mixed well with it. The only problem of using $\mathrm{CO}_{2}$ is its high back ground concentration of approximately $350 \mathrm{ppm}$ and it's exhaled amount by the people. Other tracer gases like hydrogen gas, water vapour, sulfur hexafluoride etc. have also been used in various ventilated spaces [12]. Sometimes, application of constant tracer gas concentration has been applied to estimate ACH with specific dosing and control system. The advantage of the constant concentration method is that, even with short-term changes of air supply, concentration can be detected. If a tracer gas is injected into a zone of the space, its concentration in this zone can be calculated by the following conservation equation with the assumption of uniform tracer-gas concentration in the zone:

$$
V \frac{d c}{d t}+Q C=m
$$


where, $V$ is the zone volume, $C$ is the tracer-gas concentration, $Q$ is the ventilation rate to the zone, and $\mathrm{m}$ the injection rate of the tracer gas. In the tracer-gas-concentration decay method, the tracer gas will decay due to ventilation after injection into the space is stopped [13]. This study proposed a modified tracer-gas-concentration decay method for measuring the ventilation rate in large, long, and narrow paces. The modified method also encourages the use of mixing fans in the space to achieve a more uniform distribution of tracer-gas concentration and has been compared to constant concentration method, which is regarded as the most accurate one. The modified method measured was reported about $5 \%-10 \%$ lower ventilation rate. This study may act as an important tool in developing ventilation index and exposure model in rural and urban household situations with different monitoring parameters persisting in air matrices, too.

Liuliu Du et al. conducted a study in the homes of Detroit, Michigan investigating ACRs and interzonal flows. The studied households were primarily low income and minority, and each had a child with asthma. In the houses' living area, ACRs average was found to be $0.73 \pm 0.76 \mathrm{~h}^{-1}$ (median $=0.57 \mathrm{~h}^{-1}, \mathrm{n}=263$ ). In the child's bedroom, ACRs were substantially higher with the average of $1.66 \pm 1.50 \mathrm{~h}^{-1}$ (median $=1.23 \mathrm{~h}^{-1}, \mathrm{n}=253$ ). ACRs were reported to be positively associated with recent sweeping and dusting, and indoor PM concentrations, and negatively associated with house size, the presence of a central air conditioner and smokers, indoor $\mathrm{CO}_{2}$ and VOC concentrations [14]. Therefore, the ventilation index and consequent exposure model could be developed using other relevant information like house characteristics, fuel type \& consumption, temperature etc. by measuring indoor PM concentrations and wind speed.

To calculate the ACH of a building, the use of American Society of Heating, Refrigerating and Air Conditioning Engineers (ASHRAE) minimum limit of $0.35 \mathrm{ACH}$ of the building's volume is generally adopted to determine the safety and acceptable indoor air quality of its design.

Inadequate ventilation can increase indoor pollutant levels by not bringing in enough outdoor air to dilute emissions from indoor sources and by not carrying indoor air pollutants out of the home. High temperature and humidity levels can also increase concentrations of some pollutants. In indoor environment, some sources such as building materials, furnishings, and household products like air fresheners release pollutants more or less continuously. Other sources, related to activities carried out in the home, release pollutants intermittently. These include smoking, the use of unvented or malfunctioning stoves, furnaces, or space heaters, the use of solvents in cleaning and hobby activities, the use of paint strippers in redecorating activities, and the use of cleaning products and pesticides in house-keeping. High pollutant concentrations can remain in the air for long periods after some of these activities. If too little outdoor air enters a home, pollutants can accumulate to levels that can pose health and comfort problems. Unless they are built with special mechanical means of ventilation, homes that are designed and constructed to minimize the amount of outdoor air that can "leak" into and out of the home may have higher pollutant levels than other homes. However, because some weather conditions can drastically reduce the amount of outdoor air that enters a home, pollutants can build up even in homes that are normally considered "leaky" [15].

M. Ucci et al. tried to assess the link between asthma and low ventilation rates in housing of United Kingdom. But it was found to be clearly inconclusive. The possible assumption was that the air tightness of energy-efficient dwellings might have an adverse impact on indoor air quality, provided the main pollution emitted from indoor source. In the study, the other aims were to establish the minimum ventilation rate required in a dwelling in order to control levels of moisture-related pollutants like dust mites, mould etc. that could reduce the number of respiratory hazards. Here also no significant association could be found between asthma prevalence and fitness of ventilation [16].

Sundell et al. found that elevated concentrations of House Dust Mite (HDM) allergen in mattress and floor dust were associated with the difference in absolute humidity between indoor and outdoor air, as well as with low air-exchange-rates of the home, especially in the bedroom. The study concluded that in regions with a cold winter climate, there was a correlation between infiltration and mite infestation; but air-flow rates related to number of people in the home appeared a stronger indicator of HDM infestation than air-flow rates related to home volumes [17]. Emenius et al. examined the impact of building characteristics and indoor air quality on recurrent wheezing in infants. They found that whilst building-related exposures appear to have a major impact on children's health, this was not primarily explained by differences in ventilation systems, air change rate or HDM infestation [18]. Nielsen reported ventilation measurements made in a random selection of 11 schools in Denmark. Measurements were made in 2 classrooms for 3 consecutive days. The average ventilation rate was 6.4 L/s-person with a range of $1.8-15.4 \mathrm{~L} / \mathrm{s}$-person [19]. 
Ventilation rates are rarely measured in the process of indoor air measurements in rural and urban households, though inadequate ventilation is often suspected to be an important condition leading to reported health symptoms. The ASHRAE Standard recommends a minimum ventilation rate of $8 \mathrm{~L} / \mathrm{s}$-person (15 cfm/person) for classrooms. Given typical occupant density of 33 per $90 \mathrm{~m}^{2}\left(1000 \mathrm{ft}^{2}\right)$ and a ceiling height of $3 \mathrm{~m}(10 \mathrm{ft})$, the current ASHRAE standard would require an air exchange rate of about 3 air changes per hour (ACH) for a classroom.

Among various studies performed in schools earlier, some studies provided only aggregated data while others included data for individual schools. Some data are for the same schools under different conditions such as pre and post-radon mitigation. In quite a few studies, investigators found a statistically significant partial correlation between symptoms of headaches, dizziness, heavy headed, tiredness, difficulties concentrating, unpleasant odor, and high $\mathrm{CO}_{2}$ concentrations (1500 - 4000 ppm compared to concentrations below 1500 ppm). Health symptoms characterized as "irritations of the upper airways" were also higher at higher $\mathrm{CO}_{2}$ concentrations $(p=0.024)$. Reduced performance on the Swedish Performance Evaluation System test was also observed at higher concentrations of $\mathrm{CO}_{2}$ [20] [21].

Turk, et al. reported ventilation measurements made in 6 non-complaint schools in the U.S. Northwest-2 in Portland, Oregon and 4 in Spokane, WA. Schools ranged from 3 - 25 years in age, 1 - 3 stories; all had mechanical ventilation systems of some type. Ventilation rates, calculated on a whole building volume basis, ranged from $4.5 \mathrm{~L} / \mathrm{s}$-person to $31 \mathrm{~L} / \mathrm{s}$-person. The whole or average building rate, however, included unoccupied areas such as hallways and gymnasiums, and, as the authors pointed out that the average rate overestimated the local ventilation rate of occupied classrooms. For example, in one of the elementary schools, the whole building ventilation rate was $4.5 \mathrm{~L} / \mathrm{s}$ person while the ventilation rate in an occupied classroom was only $1.6 \mathrm{~L} / \mathrm{s}-\mathrm{person}$ [22] [23].

Koskinen, et al. compared respiratory symptoms and infections in children (3 - 7 years old) in two daycare centers with visible mold growth on interior walls (exposed children) to those in two reference daycare centers (non exposed children). Parents recorded their children's $(\mathrm{N}=229)$ health symptom status in diary questionnaires during two study periods. During the first period, the children in the two daycare centers with mold problems (exposed) had a significantly increased risk of sore throat, purulent and non-purulent nasal discharge, nasal congestion, hoarseness and common cold than those in the two reference daycare centers (non-exposed). During the second follow-up period, a significantly increased risk of purulent nasal discharge, nasal congestion, hoarseness and cough was observed for the exposed populations compared to the unexposed. Overall morbidity for respiratory symptoms and common cold were higher in the daycare centers with the mold than in the two reference day care centers [24].

Sometimes, the presence of both indoor contaminants and other indoor environmental factors makes it difficult to identify direct causes of occupant discomfort and health symptoms. Ventilation surrogates the Indoor Air Quality (IAQ) level, minimizing the concentration of harmful pollutant. The higher ventilation rates are associated with improved health. On the other hand, the health indicators are also very much depended upon the exposure to indoor air pollutants.

Improvement of ventilation in living environment is always inevitable for health. Though ventilation models are not generally considered as an exact exposure models, yet they are suitable for predicting indoor pollutant exposure concentrations arising from specific sources. If full ranges and distributions of the input data are available in indoor rooms or homes in a suburb, ventilation models can be run for probabilistic simulation of the whole range of indoor exposure concentrations for the target population [25].

While progressing towards exposure model development through the measurement of ventilation rate in household level, one has to consider the recognized contributing factors that create problems in indoor air quality followed by adverse health effects. Thus, exposure model is important in indoor environment because people spend a substantial proportion of their time at home. In order to assess the total air exposure, it is crucial to take into account of both the indoor and outdoor exposures. Most of the people spend majority of their life in indoors. It means that the indoor pollution levels can substantially influence the total air exposure level. In indoor environments, tobacco smoke and combustion of solid fuels for cooking and heating are the most significant sources. In addition, construction material, furniture, carpeting, air conditioning, and home cleaning agents and insecticides can also be significant sources of chemical and biological indoor-pollutants. It has been estimated that approximately half the world's population, and up to $90 \%$ of rural households in developing countries, still rely on biomass fuels. Although the portion of global energy derived from biofuel has fallen from $50 \%$ in 1900 to 
around 13\% currently, this trend has leveled and there is evidence that biofuel use is increasing among the poor [26]. For this class of people, a dual impact of simple awareness on ventilation and cost effective measurements can reduce down the exposure arising out from the biomass fuel use, and would be more effective for women and children.

Household characteristics with poor ventilating rooms might correlate strongly between the exposure to air pollution and continuous usage of biomass fuel. Biomass fuel refers to any plant or animal based material deliberately burned by humans. Wood is the most common biomass fuel, but use of animal dung and crop residues is also widespread. It may have some economical favours while the cooking is done for joint family members with its cheap available sources. In most of the cases, these fuels are burned indoors in a traditional mud and, or brick made chulhas (A U-shaped construction for cooking), which burn these fuels inefficiently and are often not vented with flues or hoods to take the pollutants to the outside. Animal dung is on the lowest rung of the ladder progressing to crop residues, wood, charcoal, kerosene, gas, and finally electricity. People generally move up the ladder as socio-economic conditions improve.

Other sources of indoor air pollution in developing countries include smoke entering the home from nearby houses, burning of forests, agricultural land and household waste, the use of kerosene lamps, and industrial and vehicle pollution. This scenario of polluted indoor environment is known from the decade past, but the significant change in exposure situation is still challenging due to poor socioeconomic condition, lack of awareness to exposure, traditional mindset and poor administrative intervention with respect to exposure control. Many efforts to address air pollution have done little to alleviate its total impact. In such situation, in spite of looking into the emission source profile alone, equal importance has to be given to change the physical environment of the households where establishment of the ventilation index may play a vital role to develop exposure model for assessing indoor air quality without air monitoring complexities [27].

Fresh air is inevitable to all types of inhabitants in urban and rural settings and the requirement for air is relatively constant about $10-20 \mathrm{~m}^{3}$ per day [28]. There is also a risk of droplet infection and lowered resistance to diseases on prolonged exposure. The assumption that the outdoor air is 'clean' from a scientific point of view surely not true but it is a fact that the rural air is in many places still of a rather good quality, which allows for most cases to assume that such outdoor air is indeed 'clean'. However, this is surely not the case for specific applications and for certain groups of the population sensitive to allergic reactions.

Ventilation influences in various ways the amount of indoor and outdoor air exposure. Optimum control of the air change rate is therefore important. However, there is a clear lack of precise and scientifically well argued target values in relation to the air pollution levels and, therefore also of the ventilation levels. Ventilation is the supply and removal of air by either passive means - where air movement is driven by wind and temperature differences through openings such as windows; or by active means-where the air is supplied and/or extracted by mechanical methods such as ducts and fans. Ventilation is required for two separate functions: a) In cold weather - to provide air for breathing and to provide fresh air to maintain IAQ; b) In warm weather-to provide air for breathing, to maintain IAQ and to provide air movement for thermal comfort.

Ventilation in cold weather requires well-controlled air movement to meet the minimum needs of air quality and comfort. Excessive ventilation can lower the temperature. The rate at which oxygen is consumed and $\mathrm{CO}_{2}$ is produced rises rapidly with increased activity. The required rate of ventilation, therefore, rises with more vigorous activities. For warm weather, ventilation from outside will only cool a space if the outside air is cooler than the inside air. In some warmer areas, it will be warmer outside than inside. It is not just the temperature of the air that cools us. Air movement lowers the perceived temperature, cooling us by evaporating our sweat. In warm weather we need to maintain a steady flow of air for comfort. Air movement can be caused by wind, natural convection-hot air rises and active (mechanical) means e.g., fans. Wind pressures are positive (push) on the windward side of the building and negative (suck) on the leeward side. This encourages good cross-ventilation in rooms with windows on opposite sides. Cross-ventilation must be carefully controlled to prevent too much air movement in windy conditions. Wind cannot move the air through a room when there are only windows on one side. Winds can have an effect on air changes in rooms up to eight meters deep, depending on wind strength. However, effective ventilation may only be possible in shallower rooms i.e., no deeper than 2.5 times the ceiling height. All the aforesaid parameters discussed are inevitable spices for making exposure model.

Mechanical ventilation is basically a method of delivering fresh air to the space using fans and ducts. The concentration of $\mathrm{CO}_{2}$ in a room is often used as a guide to the quality of indoor air. Indoor concentrations above about 1000 parts per million (ppm) $\mathrm{CO}_{2}$ indicate that IAQ is unacceptable. Humidity is an important factor in 
controlling thermal comfort and air quality. In buildings when the relative humidity is high and surface temperatures are low, condensation forms on the surfaces. The moisture from the air turns into water. Condensation is more obvious on cold surfaces like glass, but is not always so noticeable on plasterboard walls. In July 2005, an indoor air quality field study entitled "Ventilation and Indoor Air Quality in New Homes" was conducted in USA to assist in answering some of the questions regarding ventilation and indoor air quality in new single-family detached homes. This field studies involved 108 new single-family homes from Northern and Southern California, including a subset of 26 homes with mechanical outdoor-air ventilation systems. The field teams measured home ventilation and indoor contaminant source characteristics, including the amount of composite wood associated with cabinetry/furnishings and the finishes of floors, walls, and ceilings; indoor contaminant concentrations; the residents' ventilation practices; IAQ perceptions; and decision factors regarding ventilation and IAQ-related actions. Measurements of indoor and outdoor air quality and ventilation parameters were made in the summer, fall, and winter. Indoor air concentrations of volatile organic compounds; aldehydes (including formaldehyde); $\mathrm{PM}_{2.5}$ particulate matter; nitrogen dioxide; carbon monoxide; carbon dioxide; temperature; and relative humidity were measured over 24-hour period. The outdoor air ventilation rates were determined concurrent with the air contaminant measurements using passive perfluoro carbon tracer (PFT) gas measurements. In addition, the field teams measured the building envelope air leakage, garage-to-home air leakage, forced air unit duct leakage, window use, airflow rates, and fan system usage. Twenty of the 108 homes were tested in both the summer and winter seasons, and four homes were tested in the summer, fall, and winter. Four homes were tested over multiple days, including weekends. This study provides, for the first time, statewide, accurate and current information on both ventilation and IAQ in new California homes. Indoor air quality and household ventilation practices were obtained from multiple seasons and regions of the state, which helped characterizing the full range of indoor air contaminant exposure in such homes. Measured levels of ventilation and IAQ were compared to current guidelines and standards. Information on the use of windows, fans, and central systems helped establishing realistic values for developing California building energy efficiency standards. The Energy Commission used the study results as a scientific basis to revise the state's building energy efficiency standards, in order to provide more healthful, energy-efficient homes in California [29].

Cheng K. C. et al. conducted a study on modeling exposure close to an indoor air pollution source. An isotropic turbulent diffusion coefficient was used to represent the average spread of emissions. However, its magnitude indoors was difficult to assess experimentally due to limitations in the number of monitors available. A number of real-time monitors were used to simultaneously measure $\mathrm{CO}$ at different angles and distances from a continuous indoor point source. For 11 experiments involving two houses, with natural ventilation conditions ranging from $<0.2$ to $>5$ air changes per $\mathrm{h}$, an eddy diffusion model was used to estimate the turbulent diffusion coefficients, which ranged from 0.001 to $0.013 \mathrm{~m}^{2} \cdot \mathrm{s}^{-1}$. The model reproduced observed concentrations with reasonable accuracy over radial distances of $0.25-5.0 \mathrm{~m}$. The air change rate, as measured using a $\mathrm{SF}_{6}$ tracer gas release, showed a significant positive linear correlation with the air mixing rate, defined as the turbulent diffusion coefficient divided by a squared length scale representing the room size [30].

Breen M. S. et al. published an overview and critical analysis of the scientific literature on empirical and physically based AER models for residential and commercial buildings; the models highlighted here are feasible for exposure assessments as extensive inputs are not required. Models are included for the three types of airflows that can occur across building envelopes: leakage, natural ventilation, and mechanical ventilation. Guidance is provided to select the preferable AER model based on available data, desired temporal resolution, types of airflows, and types of buildings included in the exposure assessment. For exposure assessments with some limited building leakage or AER measurements, strategies are described to reduce AER model uncertainty [31].

In Guatemala, use of wood as a fuel source was associated with an adjusted 63-g lower birth weight (BW) compared with electricity or gas, and in Zimbabwe use of high-pollution fuel (wood, dung or straw) was associated with an adjusted 175-g lower BW compared with low-pollution fuel sources. A 104.5-g lower mean BW was observed after adjusting for confounding factors in a population with $430 \%$ of babies born with weight < $2500 \mathrm{~g}$ [32] [33].

However, none of the articles published in the area of ventilation and exposure has been found to have strong opinion for implementing ventilation protocol in residential households. A study by James M. Tielsch et al. [34] revealed that the indoor particulate and gaseous exposures resulting from the use of biomass fuel sources at home are associated with significant adverse health effects on the fetus and young infant including poor intrauterine growth (IUG), excess respiratory morbidity, poor postpartum growth and increased early infant mortality, 
although the strength of evidence for the mortality association was only modest. Likewise, so many publications revealed the association between indoor particulates and respiratory health outcomes for the dwellers.

For attaining better air quality, improvement of room ventilation has been plasticized to be more convenient and feasible for most of the residential households in the world. But, for growing concern of health effects due to degraded indoor air, periodic checkup of air quality has become an important challenge for all of us. An alternate cost-effective semi-quantitative way of estimating indoor air pollution has become a longstanding demand among scientific communities as well. In this context, using room index and indoor ventilation data along with a few meteorological parameters like temperature, relative humidity, wind direction etc. may play a crucial role in validating association between ventilation and indoor air pollutants. The crucial part of this model is to minutely observe changes of a specific pollutant concentration with respect to changing ventilation status in the households. Once, the data set is validated with the available gold standard methods, it would be a control banding approach for estimating indoor air pollution in many rural and urban households with equivalent room space, temperature, relative humidity, number of residents and fuel source.

\section{Conclusion}

There is general consensus that a link exists between ventilation rates and concentration of air pollutants in indoor environment which may subsequently correlate health outcomes. To reduce laboratory costs, and other complexities of maintaining quality research in indoor environment, an innovative trial of assessing air pollutants with simple ventilation status could be an important endeavor. Hence, it is expected that the use of ventilation index in indoor environments may be one of the important control banding approaches in establishing exposure model for indoor air pollution. If the ventilation rate followed by its index is used for the development of exposure model, the time, labour and expenditure in indoor air monitoring research can be reduced drastically.

\section{Acknowledgements}

The authors express their sincere thanks to the Indian Council of Medical Research (ICMR) for providing a research grant (ICMR-CAR) to the Department of Environmental Health Engineering, Sri Ramachandra University, Chennai, India and being associated in enormous number of indoor air assessment activities in the project, the idea of this review work knocked the mind. As the scope of generating data for exposure model is still alive, it is expected to be a wonderful model in near future concerning the association between ventilation index and exposure outcomes in different household characteristics.

\section{References}

[1] http://www.livestrong.com/article/185502-outdoor-air-vs-indoor-air/

[2] WHO (2012) Burden of Disease from Indoor Air Pollution for 2012.

[3] http://www.who.int/mediacentre/news/releases/2014/air-pollution/en/

[4] http://www.epa.gov/region1/communities/indoorair.html

[5] http://www.arb.ca.gov/research/indoor/healtheffects1table1.htm

[6] Cherrie, J.W., Maccalman, L., Fransman, W., Tielemans, E., Tischer, M. and Tongeren, M.V. (2011) Revisiting the Effect of Room Size and General Ventilation on the Relationship between Near- and Far-Field Air Concentrations. Annals of Occupational Hygiene, 55, 1006-1015.

[7] http://www.bcairquality.ca/readings/ventilation-index.html.

[8] http://www.pinchin.com/sites/default/files/attachments/airbornereport_0.pdf

[9] Laussmann, D. and Helm, D. (2011) Chemistry, Emission Control, Radioactive Pollution and Indoor Air Quality. Robert Koch Institute, Berliin, 365-406.

[10] (2006) National Center for Energy Management and Building Technologies (NCEMBT-070914). Final Report, September.

[11] CEN/TC 156 (2006) Ventilation for Buildings-Calculation Methods for the Determination of Air Flow Rates in Buildings Including Infiltration.

[12] http://www.intechopen.com/

[13] Chao, J., Mu, X., Xue, Y., Li, F., Li, W., Lin, C.H., Pei, J. and Chen, Q. (2013) A Modified Tracer-Gas-Concentration 
Decay Method for Ventilation Rate Measurements in Large, Long, and Narrow Spaces. Indoor and Built Environment. http://dx.doi.org/10.1177/1420326X13487743

[14] Du, L., Batterman, S., Godwin, C., Chin, J.Y., Parker, E., Breen, M., Brakefield, W., Robins, T. and Lewis, T. (2012) Air Change Rates and Interzonal Flows in Residences, and the Need for Multi-Zone Models for Exposure and Health Analyses. International Journal of Environmental Research and Public Health, 9, 4639-4662.

[15] http://www.epa.gov/iaq/ia-intro.html

[16] Ucci, M., Ridley, I., Pretlove, S., Davies, M., Mumovic, D., Oreszczyn, T., McCarthy, M. and Singh, J. (2004) Ventilation Rates and Moisture-Related Allergens in UK Dwellings. 2nd WHO International Housing and Health Symposium, Vilnius, 29 September-4 October 2004, 328-334.

[17] Sundell, J., Wickman, M., Pershagen, G. and Nordvall, S.L. (1995) Ventilation in Homes Infested by House-Dust Mites. Allergy, 50, 106-112. http://dx.doi.org/10.1111/j.1398-9995.1995.tb05065.x

[18] Emenius, G., Svartengren, M., Korsgaard, J., Nordvall, L., Pershagen, G. and Wickman, M. (2004) Building Characteristics, Indoor Air Quality and Recurrent Wheezing in Very Young Children (BAMSE). Indoor Air, 14, 34-42. http://dx.doi.org/10.1046/j.1600-0668.2003.00207.x

[19] Nielsen, O. (1984) Quality of Air and the Amount of Fresh Air in Classrooms. Indoor Air: Buildings, Ventilation and Thermal Climate. In: Berglund, B., Lindvall, T. and Sundell, J., Eds., Swedish Council for Building Research, 5, 221226.

[20] Seppänen, O.A., Fisk, W.J. and Mendell, M.J. (1999) Association of Ventilation Rates and $\mathrm{CO}_{2}$ Concentrations with Health and Other Responses in Commercial and Institutional Buildings. Indoor Air, 9, 226-252. http://dx.doi.org/10.1111/j.1600-0668.1999.00003.x

[21] Apte, M.G., Fisk, W.J. and Daisey, J.M. (2000) Associations between Indoor $\mathrm{CO}_{2}$ Concentrations and Sick Building Syndrome Symptoms in US Office Buildings: An Analysis of the 1994-1996 BASE Study Data (LBNL 44385). Indoor Air, 10, 246-257. http://dx.doi.org/10.1034/j.1600-0668.2000.010004246.x

[22] Turk, B.H., Grimsrud, D.T., Brown, J.T., Geisling-Sobotka, K., Harrison, J. and Prill, R.J. (1987) Commercial Building Ventilation Rates and Particle Concentrations. In: Proceedings of Indoor Air'87: The 4th International Conference on Indoor Air Quality and Climate, West Berlin, 17-21 August 1987, 610-614.

[23] Turk, B.H., Grimsrud, D.T., Brown, J.T., Geisling-Sobotka, K., Harrison, J. and Prill, R.J. (1989) Commercial Building Ventilation Rates and Particle Concentrations. ASHRAE Transactions, 95, 422-433.

[24] Koskinen, O.M., Husman T.M., Hyvärinen, A.M., Reponen, T.A. and Nevalainen, A.I. (1997) Two Moldy Day-Carecenters: A Follow-Up Study of Respiratory Symptoms and Infections. Indoor Air, 7, 262-268. http://dx.doi.org/10.1111/j.1600-0668.1997.00005.x

[25] Indoor Air Quality Models. http://www.integrated-assessment.eu/node/227

[26] World Resource Institute, UNEP, UNDP, World Bank (1998-1999) World Resources: A Guide to the Global Environment. Oxford University Press, Oxford.

[27] http://cdn.intechopen.com/pdfs/16341/InTech-Air_quality_in_rural_areas.pdf

[28] Park, K. (2009) Park’s Text Book of Preventive and Social Medicine. 20th Editon, M/s Banarasidas Bhanot Publishers, Jabalpur, 639.

[29] Ventilation and Indoor Air Quality in New Homes (2009) Peer Collaborative Report. California Environmental Protection Agency, Air Resources Board, CEC-500-2009-085.

[30] Cheng, K.C., Acevedo-Bolton, V., Jiang, R.T., Klepeis, N.E., Ott, W.R., Fringer, O.B. and Hildemann, L.M. (2011) Modeling Exposure Close to Air Pollution Sources in Naturally Ventilated Residences: Association of Turbulent Diffusion Coefficient with Air Change Rate. Environmental Science \& Technology, 45, 4016-4022. http://dx.doi.org/10.1021/es103080p

[31] Breen, M.S., Schultz, B.D., Sohn, M.D., Long, T., Langstaff, J., Williams, R., Isaacs, K., Meng, Q.Y., Stallings, C. and Smith, L. (2013) A Review of Air Exchange Rate Models for Air Pollution Exposure Assessments. Journal of Exposure Science and Environmental Epidemiology.

[32] Mishra, V., Dai, X., Smith, K.R. and Mika, L. (2004) Maternal Exposure to Biomass Smoke and Reduced Birth Weight in Zimbabwe. Annals of Epidemiology, 14, 740-747. http://dx.doi.org/10.1016/j.annepidem.2004.01.009

[33] James, M.T., Joanne, K., Ravilla, D.T., Christian, L.C., Sheeladevi, S., Elizabeth, L.Y. and Rahmathullah, L. (2009) Exposure to Indoor Biomass Fuel and Tobacco Smoke and Risk of Adverse Reproductive Outcomes, Mortality, Respiratory Morbidity and Growth among Newborn Infants in South India. International Journal of Epidemiology, 38, 13511363. http://dx.doi.org/10.1093/ije/dyp286

[34] Boy, E., Bruce, N.G. and Delgado, H. (2002) Birth Weight and Exposure to Kitchen Wood Smoke during Pregnancy in Rural Guatemala. Environmental Health Perspectives, 110, 109-114. 